\title{
Propriedades terapêuticas da espécie Schinus terebinthifolius Raddi (aroeira-vermelha)
}

\author{
Therapeutic properties of the species Schinus terebinthifolius Raddi (aroeira-vermelha)
}

Propiedades terapéuticas de la especie Schinus terebinthifolius Raddi (aroeira-vermelha)

Maria do Carmo Rodrigues Maia ${ }^{1 *}$, Carolayne da Silva Laurentino ${ }^{1}$, Gabriela Araújo Carneiro ${ }^{1}$, laly Cássia da Silva Muniz ${ }^{1}$, lasmin Ingrid da Silva Muniz' ${ }^{1}$, Iran Alves da Silva ${ }^{1}$, Juliana de Azevedo Reis ${ }^{1}$, Rozana Firmino de Souza Sultanun ${ }^{1}$, Thayany Ruanny Leite Cachoeira de Vasconcelos ${ }^{1}$, Risonildo Pereira Cordeiro'1.

\section{RESUMO}

Objetivo: Identificar através da literatura científica as propriedades terapêuticas da espécie Schinus terebinthifolius Raddi (aroeira-vermelha). Revisão bibliográfica: Nesse sentido, Schinus terebinthifolius Raddi, pertence à família Anacardiaceae, essa espécie é conhecida popularmente como aroeira-vermelha, e é uma planta nativa do Brasil. Ademais, é comumente utilizada pelos brasileiros para fins medicinais e desperta, consideravelmente, um interesse na área científica por conta de suas atividades terapêuticas. Assim, os extratos das folhas, cascas do caule e o óleo essencial dos frutos da aroeira-vermelha são os principais responsáveis pela capacidade inibitória de microrganismos potencialmente patogênicos, atividade antioxidante, combate a processos inflamatórios, proporciona uma eficaz cicatrização, além de atuar contra larvas de mosquitos, especificamente os gêneros Stegomia e Aedes. As principais substâncias descritas por tais propriedades medicinais da classe dos flavonoides, saponinas, terpenos e taninos. Considerações finais: Estudos presentes na literatura científica demonstraram diversas atividades terapêuticas, como propriedades antimicrobiana, antioxidante, anti-inflamatória, eficácia no processo de cicatrização e larvicida. Ademais, destaca-se a necessidade de realização de estudos mais aprofundados com Schinus terebinthifolius Raddi, para garantir uma maior segurança em seu uso e maior eficácia da sua terapêutica.

Palavras-chave: Anacardiaceae, Fitoterapia, Plantas medicinais.

\begin{abstract}
Objective: This article sought to identify through the scientific literature the therapeutic properties of the species Schinus terebinthifolius Raddi (aroeira-vermelha) Bibliographic review: In this sense, Schinus terebinthifolius Raddi, belongs to the Anacardiacea family, this species is popularly known as aroeiravermelha, and is a plant native to Brazil. Furthermore, it is commonly used by Brazilians for medicinal purposes and arouses considerable interest in the scientific field due to its therapeutic activities. Thus, leaf extracts, stem bark and essential oil from aroeira-vermelha fruits are mainly responsible for the inhibitory capacity of potentially pathogenic microorganisms, antioxidant activity, combating inflammatory processes, providing effective healing, in addition to acting against larvae mosquitoes, specifically the genera Stegomia and Aedes. The main substances described for such medicinal properties are composed of the class of flavonoids, saponins, terpenes and tannins. Final considerations: Studies in the scientific literature have demonstrated several therapeutic activities, such as antimicrobial, antioxidant, anti-inflammatory properties, effectiveness in the healing process and larvicide. In addition, the need for more in-depth studies with an Schinus terebinthifolius Raddi is highlighted, to ensure greater safety in its use and greater effectiveness of its therapy.
\end{abstract}

Keywords: Anacardiaceae, Phytotherapy, Medicinal plants.

${ }^{1}$ Centro Universitário Tabosa de Almeida (Asces-Unita), Caruaru - PE.

*E-mail: mariarodriguesmaia93@gmail.com

SUBMETIDO EM: 2/2021 


\section{RESUMEN}

Objetivo: Este artículo buscó identificar a través de la literatura científica las propiedades terapéuticas de la especie Schinus terebinthifolius Raddi (aroeira-vermelha). Revisión bibliográfica: En este sentido, Schinus terebinthifolius Raddi, pertenece a la familia Anacardiacea, esta especie es conocida popularmente como aroeira-vermelha, y es una planta originaria de Brasil. Además, es comúnmente utilizado por los brasileños con fines medicinales y despierta un interés considerable en el campo científico debido a sus actividades terapéuticas. Así, los extractos de las hojas, corteza del tallo y el aceite esencial de los frutos de aroeiravermelha son los principales responsables de la capacidad inhibidora de microorganismos potencialmente patógenos, actividad antioxidante, combatiendo procesos inflamatorios, proporcionando una curación eficaz, además de actuar frente en las larvas de mosquitos, específicamente los géneros Stegomia y Aedes. Las principales sustancias descritas por tales propiedades medicinales en la clase de flavonoides, saponinas, terpenos y taninos. Consideraciones finales: Los estudios en la literatura científica han demostrado diversas actividades terapéuticas, como propiedades antimicrobianas, antioxidantes, antiinflamatorias, efectividad en el proceso de curación y larvicida. Además, se destaca la necesidad de realizar estudios más profundos con Schinus terebinthifolius Raddi, para garantizar una mayor seguridad en su uso y una mayor efectividad de su terapia.

Palabras clave: Anacardiaceae, Fitoterapia, Plantas medicinales.

\section{INTRODUÇÃO}

O emprego de plantas medicinais com o propósito de recuperar ou manter a saúde é uma prática a qual está em constante presença na história da humanidade, assim possuindo uma datação ainda em discussão pela literatura científica (KALIDINDI N, et al., 2015; OLIVEIRA EVS, 2016). Estima-se que $80 \%$ da população mundial faça uso da fitoterapia na atenção primária a saúde, onde várias espécies vegetais são empregadas para o tratamento e profilaxia de uma variedade de enfermidades (KALIDINDI N, et al., 2015).

A prática da fitoterapia foi disseminada ao longo do tempo, sendo utilizada durante milhares de anos, baseada em conhecimentos populares e transmitida por gerações. Atualmente é adotada como fonte de novas substâncias ativas de interesse farmacêutico, ocorrendo a descoberta de novos compostos bioativos seguros e eficientes frente as mais diversas doenças (BESRA M e KUMAR V, 2018). Neste sentido, os produtos naturais são responsáveis, direta ou indiretamente, por cerca de $40 \%$ de todos os fármacos disponíveis na terapêutica moderna, com isso, a presença da utilização desses produtos é um fato presente na humanidade (BESRA M e KUMAR V, 2018; SILVA NCS, et al., 2016).

Remetendo ao contexto nacional, o Brasil é um dos países mais diversificados do mundo no que se refere às suas espécies vegetais. Este país possui aproximadamente 46.096 plantas em mais de nove diferentes ecossistemas, sugerindo um importante e expansível campo o qual pode proporcionar maior realização de pesquisas as quais envolvam a fitoterapia. Buscando assim, o entendimento da composição química dos extratos das plantas medicinais, de modo que possam identificar quais são os princípios ativos e as suas concentrações terapêuticas eficazes e seguras diante dos processos patológicos (OLIVEIRA EVS, 2016).

Torna-se necessária a realização de estudos sobre o conhecimento e uso de recursos naturais pela população, analisando o impacto de suas práticas sobre a biodiversidade. Na atualidade, observa-se um progressivo interesse pela fitoterapia, situação a qual pode ser constatada pelos altos valores gastos das indústrias farmacêuticas na produção de fármacos sintéticos. A fitoterapia passa por uma intensa investigação científica, e é dita como uma importante fonte para novos produtos biologicamente ativos (SANTOS CTC, et al., 2019; SILVA NCS, et al., 2016).

Ainda que tenha constituído a base da terapêutica medicamentosa até o surgimento da síntese química, a fitoterapia continua em lugar de destaque na sociedade (SILVA NCS, et al., 2016). Tal terapia firma-se simultaneamente como parte da cultura de um povo. Uma grande justificativa para a adesão da população quanto ao uso da fitoterapia é que alguns indivíduos desenvolveram uma forma mais natural de vida, adquirindo convicção a qual as espécies vegetais são saudáveis e seguras. (STEFANELLO S, et al., 2018). 
Neste sentido, uma das espécies amplamente empregadas na fitoterapia é a aroeira-vermelha (Schinus terebinthifolius Raddi), as indicações de uso no meio popular são bastantes diversificadas dentre elas se destacam o uso como adstringente, antimicrobiano, cicatrizante e anti-inflamatório, com destaque para a utilização das folhas e cascas do caule. Muitas das propriedades bioativas desta espécie são atribuídas aos diferentes tipos de polifenóis distribuídos nas suas cascas, folhas, flores, frutos e sementes (SANTOS CTC, et al., 2019). Tais compostos possuem grande importância para a fisiologia da espécie, contribuindo para sua defesa e contra predadores, de modo que proporcione a integralidade do vegetal frente ao seu habitat (SANTOS OJD, et al., 2013).

As principais atividades terapêuticas desta espécie estão relacionadas as suas folhas e cascas as quais possuem elevadas concentrações de taninos e óleos essenciais (AZEVEDO CF, et al., 2015). Tendo em vista que a aroeira-vermelha é uma espécie bem utilizada na medicina popular, este artigo objetivou identificar as propriedades terapêuticas da Schinus terebinthifolius Raddi com base em pesquisas disponíveis na literatura científica.

\section{REVISÃO BIBLIOGRÁFICA}

A espécie Schinus terebinthifolius Raddi é popularmente conhecida como aroeira, pimenta-rosa, aroeirada-praia e aroeira-vermelha, tais nomenclaturas populares são variáveis de acordo com a região a qual é encontrada no território brasileiro (NEVES EJM, et al., 2016). Pertence à família botânica Anacardiaceae, sendo esta uma família que engloba gêneros bem difundidos no Brasil como Anacardium e Mangifera (RORATO DG, et al., 2018). Schinus terebinthifolius Raddi é uma espécie vegetal originária da América do Sul, compreendendo o Brasil, Paraguai, Uruguai e Leste da Argentina (AZEVEDO CF, et al., 2015). No Brasil, sua presença ocorre comumente no Nordeste do estado de Pernambuco e na região Sul do Rio Grande do Sul (NEVES EJM, et al., 2016).

Schinus terebinthifolius Raddi é uma árvore com aproximadamente cinco a dez metros de altura. Já o seu tronco é normalmente caracterizado por ser curto, com copa larga, cilíndrico e pouco denso. Possuindo casca externa do tronco é escura, grossa, rugosa e áspera que se desprende em placas irregulares. Já a casca interna se apresenta na tonalidade avermelhada, fibrosa e odor característico com exsudação de terebintina (NEVES EJM, et al., 2016; RORATO DG, et al., 2018). As flores da aroeira-vermelha são actinomorfas, pentâmeras, com cinco sépalas verdes, cinco pétalas brancas e disco nectarífero amarelo ouro. Com fruto globoso e levemente achatado, o qual contém sementes ortodoxas (NEVES EJM, et al., 2016).

Já suas folhas são do tipo perenifólias, liberam forte aroma e possuem filotaxia alterna. A aroeira-vermelha exibe a presença de componentes estruturais característicos de plantas xerófilas, sendo a camada múltipla da epiderme da face adaxial foliar, a qual atua na proteção do mesofilo de excessiva dessecação. Apresenta ainda cutículas espessas e um considerável quantitativo de pelos e de estômatos, além de sistema vascular bem desenvolvido, com predominância de esclerênquima, proporcionado a sustentação ao feixe (AZEVEDO CF, et al., 2015; RORATO DG, et al., 2018). Assim, esta planta adapta-se facilmente a solos com restrições hídricas, físicas, químicas e em regiões com baixas temperaturas propensas a geadas, sendo recomendada para áreas de reflorestamento (RORATO DG, et al., 2018).

A indústria alimentícia possui grande interesse nos frutos de aroeira-vermelha devido às suas características de sabor e aroma (ULIANA MP, et al., 2016). Sendo assim, os frutos de Schinus terebinthifolius Raddi são comumente usados como tempero, enquanto a casca, as folhas e as raízes são constituintes tradicionais da medicina popular, devido às suas propriedades anti-inflamatórias, antipiréticas e analgésicas (CARVALHO MG, et al., 2013).

A aroeira-vermelha tem sido amplamente estudada acerca de suas propriedades terapêuticas, com destaque para as atividades antimicrobianas, antioxidantes, anti-inflamatório, cicatrizante e larvicidas (SILVA AG, et al., 2010; SILVA-NETO R, et al., 2018). Diversos estudos comprovam a ação antimicrobiana dos frutos da aroeira-vermelha, associando-a com sua composição química rica em álcoois, ácidos, monoterpenos, cetonas, triterpenos, sesquiterpenos entre outros componentes químicos (SANTOS CTC, et al., 2019). 
Identificou-se antocianinas, biflavonoides e galotaninos na composição fenólica do exocarpo de Schinus terebinthifolius Raddi (FEUEREISEN MM, et al., 2014). O óleo essencial desta espécie possui $4,97 \%$ de monoterpenos, $56,96 \%$ de sesquiterpenos, $34,37 \%$ de monoterpenos oxigenados e $3,32 \%$ de sesquiterpenos oxigenados. Os principais compostos do óleo essencial são cis-beta-terpineol, (E) -cariofileno (17,56\%), betacedreno $(9,76 \%)$ e citronelal $(7,03 \%)$ (EL-MASSRY KF, et al., 2009). Pesquisadores conseguiram isolar e identificar a predominância de monoterpenos como $\alpha$-pineno, $\beta$-Pineno, mirceno e limoneno, seguidos de menor concentração de sesquiterpenos como D-germacreno, no óleo essencial de Schinus terebinthifolius Raddi (GOIS FD, et al., 2016).

\section{Propriedades Antimicrobianas}

Através de experimentos foi verificado que os frutos da aroeira também apresentaram atividade antimicrobiana frente a Staphylococcus aureus, bactéria que em pacientes com deficiência do sistema imune podem desencadear processos patológicos os quais podem estar relacionados com a sua sobrevida (SILVA GBPG, et al., 2017). As partes aéreas de Schinus terebinthifolius Raddi, mais especificamente as folhas, são capazes de inibir o crescimento de espécies potencialmente patogênicas ao ser humano e frequentes em processos infecciosos como Escherichia coli, Staphylococcus aureus, Pseudomonas aeruginosa e Candida Albicans (SILVA-NETO R, et al., 2018; ULIANA MP, et al., 2016).

O seu óleo essencial, é rico em mono, sesquiterpenos e taninos que proporcionam ações antimicrobianas, desencadeando efeitos bactericida e bacteriostática, sendo assim, um possível agente efetivo na prevenção a infecções, até mesmo em ambiente hospitalar (SANTOS CTC, et al., 2019; SILVA-NETO R, et al., 2018). Tendo em vista que a resistência bacteriana é uma problemática atual e a não erradicação de bactérias multirresistentes podem acabar acarretando a piora do quadro clínico dos pacientes e até mesmo a mortalidade (SILVA-NETO R, et al., 2018).

O óleo essencial do fruto verde da aroeira-vermelha não apresenta atividade antibacteriana, enquanto que o óleo essencial do fruto maduro é capaz de inibir, em diferentes concentrações, o crescimento de isolados de Acinetobacter baumannii produtoras de metalo-beta-lactamase e oxacilinases. Desse modo a concentração mínima inibitória foi até $0,03125 \%$, assim conclui que o óleo essencial de frutos maduros de aroeira representa uma nova possível fonte terapêutica contra isolados de Acinetobacter baumannii multirresistentes (SANTOS CTC, et al., 2019).

Em conjuntura, foi identificado no óleo essencial do fruto maduro a atividade antibacteriana contra Staphylococcus aureus (MRSA) e Staphylococcus Epidermidis resistente à meticilina (MRS) causadores de infecção hospitalar, com concentração inibitória mínima (CIM) variando de 1 a 0,5\%. Também apresentou eficácia o óleo essencial do fruto maduro frente a Klebsiella Pneumoniae produtora de carbapenemase (CIM: 2,0\%), a Escherichia coli produtora de Beta-lactamase de espectro estendido (CIM: 0,5\%) e potencial antifúngico diante da espécie Candida Albicans (CIM: 1,0\%). Em contraste, a fração do fruto verde da aroeira não apresentou ação antibacteriana e antifúngica. Desse modo, a atividade antimicrobiana está ligada com a composição química e maturação dos frutos, fator imprescindível na ação do mesmo fruto em diferente estado de maturação (BRAGA NSM, et al., 2020).

Dentre os inúmeros compostos químicos que apresentam propriedades antimicrobianas e se encontram no extrato da espécie Schinus terebinthifolius Raddi, podem-se citar o ácido hidroximasticadienóico, o ácido terebinthifólico, o ácido ursólico e a terebinthona. Ainda, é nos frutos o principal local onde se encontram os óleos essenciais (BENDAOUD H, et al., 2010).

O extrato etanólico das folhas de Schinus terebinthifolius Raddi apresentou uma atividade antimicrobiana sobre a espécie bacteriana Enterococcus Faecalis e ainda foi capaz de inibir significativamente o crescimento de Candida Albicans e Candida Tropicalis sensíveis e resistentes a fluconazol (COSTA CODS, 2011). O extrato hidroalcoólico das folhas da aroeira e o óleo essencial dos frutos da árvore apresentaram efeito antibacteriano frente às cepas de Escherichia coli da linhagem (ATCC 25922). A Escherichia Coli é uma bactéria Gram-negativa e aeróbia, a qual também está associada a quadros de infecções urinárias, na corrente sanguínea, intestinais entre outros (GREATTI VR, et al., 2014). 
A lectina isolada das folhas de Schinus terebinthifolius Raddi demonstra efeito antimicrobiano, sendo caracterizado pela determinação das concentrações mínimas de inibição (CMI), bactericida (CMB) e fungicida (CMF). A lectina foi ativa contra Escherichia coli, Klebsiella Pneumoniae, Proteus Mirabilis, Pseudomonas aeruginosa, Salmonella enteritidis e Staphylococcus aureus. Os maiores efeitos bacteriostáticos e bactericidas foram detectados para Salmonella enteritidis (CMl: $0,45 \mu \mathrm{g} \mathrm{ml}(-1)$ ) e Staphylococcus aureus (CMB: $7,18 \mu \mathrm{g} \mathrm{ml}(-1))$, respectivamente. Além disso, a aroeira-vermelha conseguiu ter um potencial inibitório ao prejudicar o crescimento (CMl: 6,5 $\mu \mathrm{g} \mathrm{ml}(-1)$ ) e a sobrevivência (CMF: $26 \mu \mathrm{g} \mathrm{ml}(-1)$ ) de Candida Albicans, um microrganismo residente da microbiota humana, mas também pode ser considerado como patógeno oportunista (GOMES FS, et al., 2013).

\section{Propriedades Antioxidantes}

Os radicais livres são capazes de provocar a oxidação celular no organismo humano e podem ainda desencadear entraves diante da homeostase corporal, ocasionando o surgimento de diversas doenças (SILVA MM, et al., 2017). Contudo, os metabólitos secundários como o ácido ferúlico, quercetina e o ácido caféico foram identificados nos extratos das folhas de aroeira-vermelha e são considerados as principais substâncias responsáveis pela grande atividade antioxidante encontrada na espécie (ULIANA MP, et al., 2016).

Os resultados dos experimentos mostraram que os compostos fenólicos, taninos hidrolisados e os flavonoides foram ativos em diversos ensaios laboratoriais, comparáveis ao antioxidante natural ácido ascórbico. Assim, os flavonoides da classe dos polifenóis, o galato de metila, e a quercetina, também são considerados antioxidantes naturais, que possuem a capacidade de minimizar ou inibir a oxidação de um substrato oxidável (SILVA-NETO R, et al., 2018).

O composto orgânico a-pineno, isolado a partir das folhas de Schinus terebinthifolius Raddi, apresentouse como um potente antioxidante e antineoplásico, capaz de induzir a apoptose. Sendo esta evidenciada por ruptura precoce do potencial mitocondrial, produção de espécies reativas de oxigênio, aumento da atividade da caspase-3, agregação de heterocromatina, fragmentação do DNA e exposição da fosfatidilserina na superfície celular. Nesse seguimento, atuando principalmente diante aos mecanismos de apoptose de células de câncer de pele do tipo melanoma (MATSUO AL, et al., 2011).

Pesquisadores avaliaram a atividade antioxidante usando reagentes de ácido 2, 2-difenil-1-picrilhidrazil, $\beta$ caroteno / linoléico e ácido 2,2'-azino-bis- (3-etilbenzotiazolina) -6-sulfônico. O óleo essencial de pimenta rosa apresentou atividade antioxidante nos três ensaios realizados em duplicata $(2,88 \pm 0,02 ; 2,31 \pm 0,06$; $2,39 \pm 0,02 \mu$ moles equivalente de trolox/g de óleo essencial de pimenta rosa). Portanto, como principal resultado deste estudo, foi encontrado que o óleo essencial dos frutos in natura de aroeira conseguiu apresentar atividade antioxidante (SILVA MM, et al., 2017). Dessa maneira, esse óleo é capaz de desencadear significativa ação preventiva a processos oxidativos, em ensaios in vitro (SILVA MM, et al., 2017; SILVA-NETO R, et al., 2018).

Ainda nessa vertente, pesquisadores analisaram que os extratos etanólicos das sementes, frutos, cascas, caule e folhas de Schinus terebinthifolius Raddi possuem maior atividade antioxidante quando comparados com extratos oriundos aquosos (COSTA CODS, 2011). Além disso, também encontraram que a concentração de fenóis totais das sementes, frutos e cascas desta espécie é superior no extrato etanólico (ULIANA MP, et al., 2016).

\section{Propriedades Anti-Inflamatórias e Cicatrizantes}

A busca por opções terapêuticas para o tratamento de processos infecciosos e cicatrização de ferimentos é crescente na atualidade, buscando compostos que minimizem a sintomatologia dos processos inflamatórios agudos, com o menor grau de agressão ao indivíduo e minimização de efeitos colaterais (AZEVEDO CF, et al., 2015; SILVA-NETO R, et al., 2018). Alguns compostos bioativos presentes na espécie Schinus terebinthifolius Raddi como taninos e flavonóides, desempenham efeitos anti-inflamatórios e cicatrizantes com grande maestria, agindo principalmente na inibição seletiva da síntese da fosfolipase A2 (SANTOS OJD, et al., 2013). 
A resposta inflamatória ausente ou excessiva no organismo é capaz de comprometer o processo de cicatrização tecidual. Neste sentido, autores destacam que a utilização do extrato hidroalcoólico de aroeiravermelha favorece a cicatrização em diversas variáveis da inflamação, sendo responsável principalmente pela estimulação a produção de colágeno, proporcionando melhores aspectos cicatriciais (SANTOS OJD, et al., 2013).

Dentre os ativos da aroeira-vermelha, as saponinas possuem propriedades tensoativas e os flavonóides são capazes de interagir com muitos radicais livres, assim formando compostos estáveis, retardando o envelhecimento das células e tendo também ação anti-inflamatória e cicatrizante eficiente (SILVA-NETO R, et al., 2018).

Em conjuntura, o extrato de folha hidroalcoólica da aroeira-vermelha apresentou-se com potencial inibitório de leucócitos (principalmente neutrófilos) migração, produção de citocinas e quimiocinas em processos inflamatórios a artrite induzida por zimosan. A mediana a dose efetiva foi de $100 \mathrm{mg} / \mathrm{kg}$, que inibiu $70 \%$ do acúmulo de neutrófilos e reduziu o diâmetro da articulação e neutrófilos influxo para tecidos sinoviais na artrite induzida por zimosan. Além disso, o extrato inibiu a interleucina sinovial (IL-6), quimiocina derivada de IL-1 beta, queratinócitos (CXCL1 / KC) e fator de necrose tumoral alfa (TNF- $\alpha$ ). Desse modo, a Schinus terebinthifolius Raddi se torna uma sugestão terapêutica para tratar doenças inflamatórias, como inflamação das articulações (ROSAS EC, et al., 2015).

Num ensaio clínico, utilizou-se uma formulação de enxaguatório bucal que continha a tintura de casca do caule de Schinus terebinthifolius Raddi a $0,3 \%$ de concentração, para a redução dos níveis de inflamação gengival em crianças. Nesse contexto, apresentou-se resultados significativos na atividade anti-inflamatória, após um regime de uso de dez dias em crianças com gengivite induzida por biofilme moderado (FREIRES IA, et al., 2013).

\section{Propriedades Larvicidas}

Atualmente, mosquitos do gênero Aedes e Stegomyia, podem transmitir doenças de interesse da saúde pública como dengue e febre amarela (SILVA AG, et al., 2010; VASCONCELOS TFP, 2014). Nesse seguimento, pesquisadores identificaram no óleo essencial de frutos e sementes da aroeira-vermelha, seis constituintes principais: $\delta$-3-careno, $\alpha$-pineno, silvestreno, germacreno $D, \beta$-mirceno e isoterpinoleno potencialmente tóxicos para tais mosquitos. $E$ ainda, a dose inibitória mínima para o desenvolvimento das larvas foi de $862,20 \mu \mathrm{g} \mathrm{mL-1}$, já a dose letal média (LD50) do óleo essencial para larvas ficou entre as concentrações de 172,44-344,88 $\mu \mathrm{g} \mathrm{mL-1}$, os dados citados indicaram que do óleo essencial de aroeiravermelha apresenta potencial larvicida natural contra S. aegypti (SILVA AG, et al., 2010).

Os derivados de ácido cinâmico e flavonoides presentes no extrato das folhas de Schinus terebinthifolius Raddi são capazes de provocarem desequilíbrios intestinais, na porção média da larva de $A$. aegypti, interferindo na sobrevivência e desenvolvimento desse inseto, nas fases a pupas e adultos. Primordialmente, a fração do extrato dessa espécie contém uma grande concentração de flavonoides, apresentando-se isenta de toxicidade para Artemia salina, segundo os testes toxicológicos realizados (VASCONCELOS TFP, 2014).

Pesquisadores observaram que o extrato das folhas de Schinus terebinthifolius Raddi mostrou-se com atividade larvicida em frente a espécie $A$. aegypti. Obtendo como resultados após a aplicação o extrato, nas concentrações entre $0,5 \%$ e $1,35 \%$, o impedimento da evolução de todas larvas, assim as mesmas não conseguiram atingir o estádio. Ainda, o extrato $(1,0 \%)$ promoveu intensa desorganização do epitélio do intestino médio larval, incluindo deformação e hipertrofia das células, rompimento de microvilosidades e vacuolização de citoplasmas, afetando células digestivas, enteroendócrinas, regenerativas e proliferativas.

Os derivados do ácido cinâmico e flavonoides estão envolvidos no efeito larvicida do extrato. A lectina presente no extrato foi isolada, mas não apresentou efeitos deletérios nas larvas. Logo, os derivados de ácido cinâmico desencadeiam efeitos larvicidas em um tempo mais curto, mas eram mais tóxicos para Artemia salina, enquanto que os flavonoides, embora os efeitos larvicidas fossem em um tempo mais longo, ficaram isentos de toxicidade na Artemia salina (PROCÓPIO TF, et al.,2015). 


\section{CONSIDERAÇÕES FINAIS}

Diante da análise dos estudos encontrados, foi possível identificar que diversos metabólitos ativos, como, flavonoides, saponinas, terpenos e taninos são capazes de desempenhar propriedades terapêuticas para a espécie Schinus terebinthifolius Raddi, estes compostos bioativos se encontram principalmente nas as folhas, frutos, óleo de essencial e cascas do caule da aroeira-vermelha. Dentre as atividades encontradas se destacam as antimicrobianas, antioxidantes, anti-inflamatórias, cicatrizantes e larvicidas. Destaca-se também a necessidade de realização de estudos mais aprofundados com Schinus terebinthifolius Raddi, cuja finalidade garanta uma maior segurança em seu uso e maior eficácia da sua terapêutica, para assim orientar melhor a população quanto a sua utilização tal como, para a formulação de novos medicamentos a partir de seus compostos bioativos.

\section{REFERÊNCIAS}

1. AZEVEDO CF, et al. Estudo farmacobotânico de partes aéreas vegetativas de aroeira-vermelha (Schinus terebinthifolius Raddi, Anacardiaceae). Revista brasileira de plantas medicinais, 2015; 17(1): 26-35.

2. BENDAOUD H, et al. Chemical Composition and Anticancer and Antioxidant Activities of Schinus Molle L. and Schinus terebinthifolius Raddi Berries Essential Oils. Journal Food Science, 2010; 75(6):466-472.

3. BESRA M, KUMAR V. In vitro investigation of antimicrobial activities of ethnomedicinal plants against dental caries pathogens.3 Biotech, 2018; 8(5): 25.

4. BRAGA NSM, et al. Ação Antibacteriana e Composição Fenólica do Óleo Essencial dos Frutos de Schinus terebinthifolius Raddi frente a Patógenos Multirresistentes. Revista Virtual de Química, 2020; 12(5):1-9.

5. CARVALHO MG, et al. Schinus terebinthifolius Raddi: chemical composition, biological properties and toxicity. Revista Brasileira de Plantas Medicinais, 2013; 15(1): 158-169.

6. COSTA CODS. Avaliação da atividade antioxidante e antimicrobiana de extratos de Myracrodruon Urundeuva Allemão e Schinus terebinthifolius Raddi. Dissertação (Pós-Graduação em Processos Interativos dos Órgãos e Sistemas) Instituto de Ciências da Saúde. Universidade Federal da Bahia, Salvador, 2011; 66 p.

7. DIAS AS, et al. In vitro activity of the Schinus terebinthifolius (R.) extract on engorged female tick of Rhipicephalus Boophilus Microplus and on larvae hatchability. Scientific Electronic Archives, 2019; 12(2) 64-69.

8. EL-MASSRY KF, et al. Chemical compositions and antioxidant/antimicrobial activities of various samples prepared from Schinus terebinthifolius leaves cultivated in Egypt. Journal of agricultural and food chemistry, 2009; 57(12): 52655270.

9. FEUEREISEN MM, et al. Characterization of phenolic compounds in Brazilian pepper (Schinus terebinthifolius Raddi) Exocarp. Journal of agricultural and food chemistry, 2014; 62(26): 6219-6226.

10. FREIRES IA, et al. A Randomized Clinical Trial of Schinus terebinthifolius Mouthwash to Treat Biofilm-Induced Gingivitis. Evidence-based complementary and alternative medicine, 2013; 2013:873907.

11. GOIS FD, et al. Effect of Brazilian red pepper (Schinus terebinthifolius Raddi) essential oil on performance, diarrhea and gut health of weanling pigs. Livestock Science, 2016; 183: 24-27.

12. GOMES FS, et al. Antimicrobial lectin from Schinus terebinthifolius leaf. Journal of applied microbiology, 2013; 114(3); 672-679.

13. GREATTI VR, et al. Avaliação da atividade antibacteriana in vitro da aroeira (Schinus terebinthifolius) e da canela (Cinnamomumzeylanicum) frente a linhagens gram positivas e gram negativas. Salusvita, 2014; 33(3).

14. KALIDINDI N, et al. Antifungal and antioxidant activities of organic and aqueous extracts of Annona squamosa Linn. leaves. Journal of food and drug analysis, 2015; 23(4): 795-802.

15. KUMAR KA, et al. Comparative in vitro anti-tick efficacy of commercially available products and newly developed phytoformulations against field collected and resistant tick lines of Rhipicephalus (Boophilus) microplus. Journal of parasitic diseases, 2016; 40(4): 1590-1596.

16. MARTORELLI SBF, et al. Efeitos antiinflamatório e cicatrizante do extrato hidroalcoólico de Schinus terebinthifolius Raddi (AROEIRA) a 30\% em orabase- estudo "In vivo". International Journal of Dentistry, 2011; 80-90.

17. MATSUO AL, et al. $\alpha$-Pinene isolated from Schinus terebinthifolius Raddi (Anacardiaceae) induces apoptosis and confers antimetastatic protection in a melanoma model. Biochemical and Biophysical Research Communications, $2011 ; 411(2): 449-454$.

18. NEVES EJM, et al. Cultivo da aroeira-vermelha (Schinus terebinthifolius Raddi) para produção de pimentarosa. Embrapa Florestas-Documentos (INFOTECA-E), 2016, 1(1): 114-117.

19. OLIVEIRA EVS. Dinâmica temporal e aspectos da vegetação em uma comunidade de caatinga. Dissertação (PósGraduação em Ecologia e Conservação) - Universidade Federal de Sergipe, São Cristóvão, 2016; 98 p.

20. PROCÓPIO TF, et al. Schinus terebinthifolius Leaf Extract Causes Midgut Damage, Interfering with Survival and Development of Aedes aegypti Larvae. PLoS One, 2015; 10(5):e0126612.

21. RORATO DG, et al. Tolerance and resilience of forest species to frost in restoration planting in southern Brazil. Restoration Ecology, 2018; 26(3): 537-542.

22. SANTOS CTC, et al. Comparação da atividade entre óleos essenciais de frutos verdes e maduros de Schinus terebinthifolius Raddi sobre isolados de Acinetobacter baumannii multirresistentes. Diversitas Journal, 2019; 4(1): 285291. 
23. SANTOS OJD, et al. Efeito de Schinus terebinthifolius Raddi (aroeira) e Carapa Guianensis Aublet (andiroba) na cicatrização de gastrorrafias. ABCD. Arquivos Brasileiros de Cirurgia Digestiva, 2013; 26(2): 84-91.

24. SILVA GBPG, et al. Antimicrobial activity of Phoma sp. URM 7221: An endophyte from Schinus terebinthifolius Raddi (Anacardiaceae). African Journal of Microbiology Research, 2017; 11(1): 1-7.

25. SILVA AG, et al. The essential oil of Brazilian pepper, Schinus terebinthifolius Raddi in larval control of Stegomyia aegypti (Linnaeus, 1762). Parasites \& vectors, 2010; 3(1): 79-83.

26. SILVA MM, et al. Schinus terebinthifolius: phenolic constituents and in vitro antioxidant, antiproliferative and in vivo anti-inflammatory activities. Revista Brasileira de Farmacognosia, 2017; 27(4): 445-452.

27. SILVA NCS, et al. Tudo que é natural não faz mal? Investigação sobre o uso de plantas medicinais e medicamentos fitoterápicos por idosos, na cidade de lapu-leste de Minas Gerais. Cadernos Acadêmicos, 2016; 2(1): 1-12.

28. SILVA-NETO R, et al. Schinus terebinthifolius Raddi: propriedades antimicrobiana, antiinflamatória e cicatrizante. Mostra Científica da Farmácia, 2018; 4(2): 1.

29. STEFANELLO S, et al. Levantamento do uso de plantas medicinais na Universidade Federal do Paraná, Palotina-PR, Brasil. Revista Extensão em Foco, Curitiba, 2018; (15): 15-27.

30. ROSAS EC, et al. Anti-inflammatory effect of Schinus terebinthifolius Raddi hydroalcoholic extract on neutrophil migration in zymosan-induced arthritis. Journal of Ethnopharmacology, 2015; 175:490-498

31. ULIANA MP, et al. Composition and biological activity of Brazilian rose pepper (Schinus terebinthifolius Raddi) leaves. Industrial Crops and Products, 2016; 83: 235-240.

32. VASCONCELOS TFP. Estudo da ação de extrato de folhas de Schinus terebinthifolius na sobrevivência e no desenvolvimento de larvas de Aedes aegypti. Dissertação (Pós-Graduação em Bioquímica e Fisiologia) - Universidade Federal de Pernambuco, Recife, 2014; 88 p. 